\title{
Waiting on a friend: Now is the time for better devices!
}

\author{
Eric E. Roselli, MD
}

\author{
From the Department of Thoracic and Cardiovascular Surgery, Aorta Center, Heart and Vascular Institute, Cleve- \\ land Clinic, Cleveland, Ohio. \\ Disclosures: Roselli is a consultant and investigator for Bolton, Cook, Gore, and Medtronic. \\ Received for publication Sept 28, 2017; accepted for publication Oct 7, 2017; available ahead of print Nov 15, \\ 2017. \\ Address for reprints: Eric E. Roselli, MD, Thoracic and Cardiovascular Surgery, Cleveland Clinic, 9500 Euclid \\ Ave, Desk J4-1, Cleveland, OH 44915 (E-mail: roselle@ ccf.org). \\ J Thorac Cardiovasc Surg 2018;155:496-7 \\ $0022-5223 / \$ 36.00$

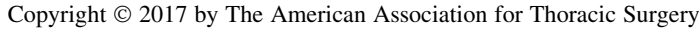 \\ https://doi.org/10.1016/j.jtcvs.2017.10.014
}

The 25th anniversary of the first thoracic stent grafting was recently celebrated at Stanford University with a Festgraft event. Several pioneers came together to discuss the history, the present state, and the future of thoracic endovascular aortic repair (TEVAR). Those original devices were handmade by physicians, and it was their courage and careful practice that allowed the development of this disruptive technology. TEVAR has become the dominant approach to treating descending aortic disease, with a continuous rise in use since it was first approved by the US Food and Drug Administration in 2005.

One of the most important fundamental principles to successful endovascular therapy is achieving delivery and deployment into a parallel-oriented, normal-caliber, and durable landing zone segment of the aorta. It was apparent early in the development of TEVAR that a large proportion of patients requiring descending thoracic aortic repair will require coverage of the left subclavian artery (LSA) to obtain adequate fixation and seal (zone 2). Most would agree that the LSA can be selectively covered, but revascularization is preferred to reduce the risk of neurologic or ischemic complications. The best method to achieve this end, however, has not been resolved.

Options for managing the left subclavian artery include hybrid solutions combining open repair, such as carotidto-LSA bypass with an interposition graft or direct LSA to common carotid transposition, with endovascular repair or totally endovascular options. Hybrid approaches to revascularize the LSA are the most commonly used, but they can also carry morbidity, and most patients would prefer the lesser invasiveness provided by a totally endovascular approach. Currently, there are no commercially available options for totally endovascular LSA revascularization.

Off-label endovascular strategies to revascularize the LSA include the following: (1) parallel grafting with grafts variously described as chimneys, periscopes, and snorkels (ChimPS); (2) the use of lasers to perform in situ fenestration of the aortic device combined with LSA stent grafting; and (3) the creation of physician-modified devices with fenestrations or branches.

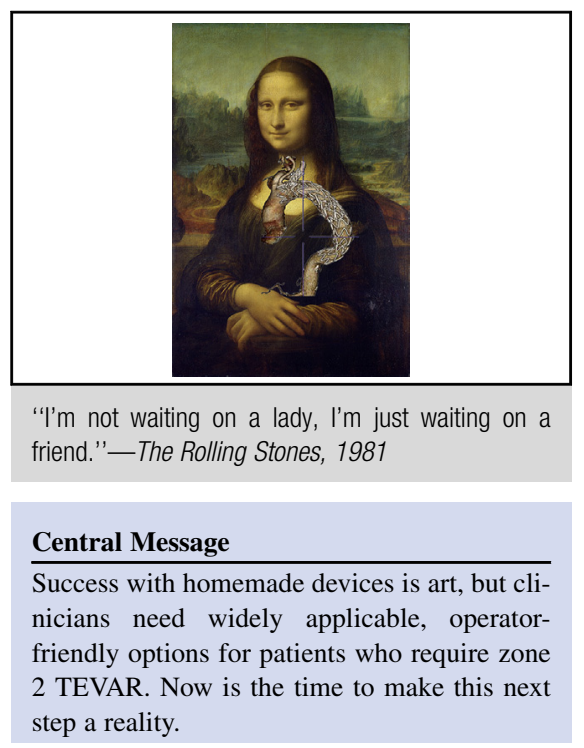

See Article page 488

Canaud and colleagues ${ }^{1}$ from 3 different centers report in this issue of the Journal their experience in 24 patients with a standardized method of creating a homemade fenestrated stent graft to maintain patency of the native LSA during TEVAR. Their results are excellent, with technical success in all reported cases and intermediate-term durability according to typical computed tomographic imaging followup at 1 year. Canaud and colleagues ${ }^{1}$ are to be congratulated on their success, but one must be exceptionally careful before trying to replicate these results. Canaud and colleagues ${ }^{1}$ are pushing the envelope with this newer procedure, but they have selected their patients carefully and follow them up closely. They only performed 24 of these operations spanning a 4-year period at 3 busy aorta centers. Although several different pathologies were included, this does not represent a consecutive TEVAR experience. It is important to recognize that there are anatomic limitations to the application of this technique. For example, the branch anatomy on the arch must be aligned in such a way that there is at least $15 \mathrm{~mm}$ between the left common carotid and the LSA, and the main body aortic device should abut the origin of the LSA. Many patients who require TEVAR will not meet these criteria, but with an understanding of the limitations of their technique, Canaud and colleagues ${ }^{1}$ were appropriately careful in its application.

Novel devices with single-branch designs are currently in clinical trials (MonaLSA; Medtronic, Inc, Minneapolis, Minn; and TBE; W.L. Gore \& Associates, Flagstaff, 
Ariz). ${ }^{2,3}$ These industry-sponsored devices go through a thorough process of iterative development and validation testing that begins on the benchtop, in simulation tanks, with finite element analyses, and animal testing before going into human trials. The human trials are closely monitored and conducted with guidance from the Food and Drug Administration. It is a requirement that new devices be evaluated for possible losses of integrity, migration, loss of seal, branch vessel compromise, stent fracture, and other possible modes of failure. Any such failures must be characterized in terms of frequency, distribution, association with clinical sequelae or potential for such, and possible mechanisms and contributing factors. These data may then require the performance of a root cause analysis and further benchtop testing directed at uncovering design or manufacturing flaws. These processes are in place to optimize safety.

Research and development teams at multiple manufacturers have found that devices resembling the homemade devices such as the one proposed by Canaud and colleagues ${ }^{1}$ failed benchtop wear testing, with stent fractures occurring as a result of excessive respiratory and cardiac motion. This is one of the reasons that the newer manufactured branch systems include novel stent grafts specifically created for the LSA branch portion of these modular systems. A homemade device does not go through the same rigorous evaluation as an approved one. On the other hand, the development and testing process takes a long time. While we wait to get through these processes, patients still demand improvements in care.

Achieving great results with a homemade device is a work of art (like the intriguing lady depicted on canvas), but what clinicians need now is a readily available, widely applicable, reliable, and operator-friendly option for patients requiring TEVAR with coverage of the LSA (like a friend). After 25 years of TEVAR, now is the time to make this next step a reality.

\section{References}

1. Canaud L, Morishita N, Gandet T, Sfeir J, Bommart S, Alric P, et al. Homemade fenestrated stent graft for thoracic endovascular aortic repair of zone 2 aortic lesions. J Thorac Cardiovasc Surg. 2018;155:488-93.

2. Roselli EE, Arko FR 3rd, Thompson MM, Valiant Mona LSA Trial Investigators. Results of the Valiant Mona LSA early feasibility study for descending thoracic aneurysms. J Vasc Surg. 2015;62:1465-71.e3.

3. Patel HJ, Dake MD, Bavaria JE, Singh MJ, Filinger M, Fischbein MP, et al Branched endovascular therapy for the distal aortic arch: preliminary results of the feasibility multicenter trial of the Gore thoracic branch endoprosthesis. Ann Thorac Surg. 2016;102:1190-8. 